\title{
THE CANCER THAT RISES WITH THE SUN
}

Melanoma is an aggressive cancer that normally starts in the skin. It can strike anyone but is most common in people with pale skin, and it is getting more common. By David Holmes.

\section{THE MARCH OF MELANOMA}

Melanoma is a cancer that starts in cells called melanocytes, which make the pigment melanin. It usually starts in a mole and is strongly linked with exposure to UVA and UVB radiation from the sun or sunbeds. However, it can occur in any tissue that contains melanocytes, such as the eye or the intestines. Genetic factors can also increase the risk of melanoma. At diagnosis, a melanoma has a numerical stage based on how deeply it has grown into the skin, and whether it has spread to other parts of the body.

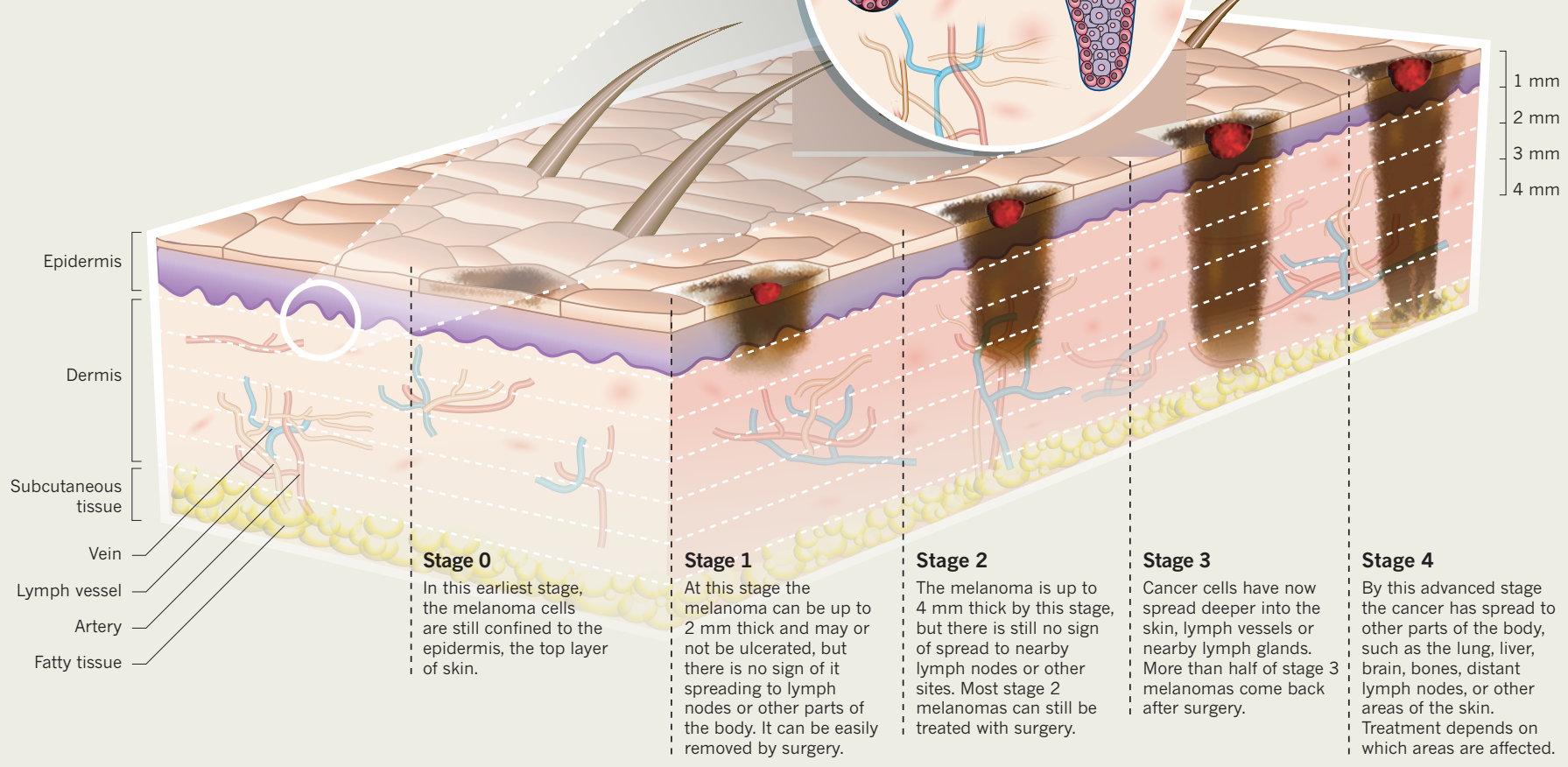

\section{INCREASING BURDEN}

The incidence of melanoma is increasing faster than that of any other solid tumour, although the mortality rate has remained largely flat. Figures shown are for the United States, where melanoma is now the fifth most common form of cancer.

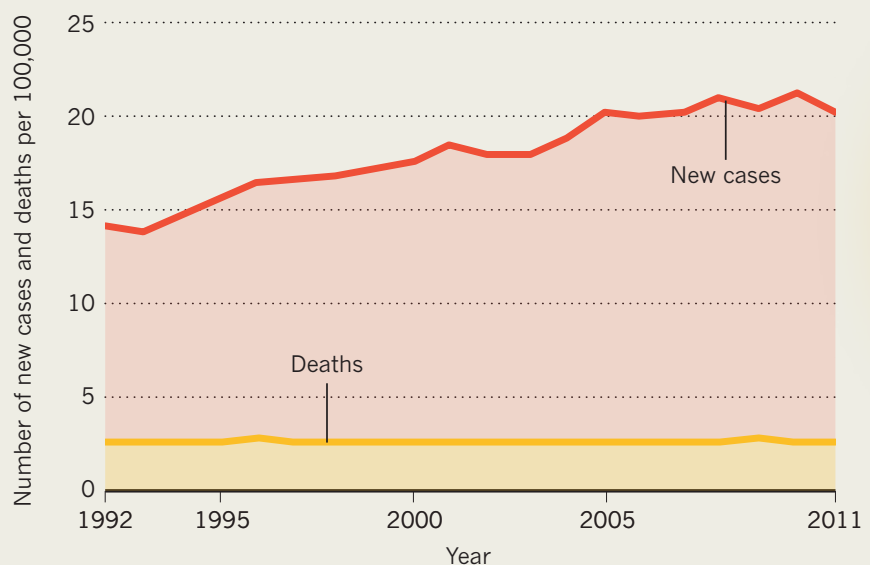

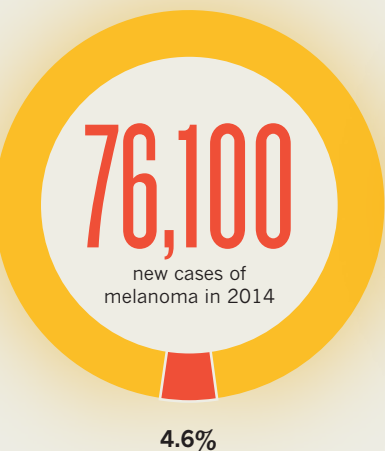

of new cancer cases

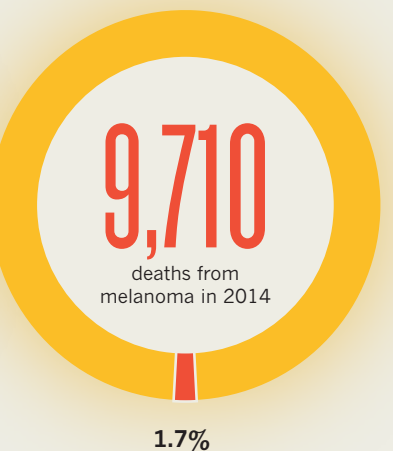

of deaths from cancer 


\section{GLOBAL INCIDENCE}

Melanoma is the 19 th most common cancer worldwide, with around 232,000 new cases diagnosed in 2012 , accounting for $2 \%$ all cancers. The highest rates of melanoma occur in countries where the inhabitants are predominantly light skinned. Northern Europe and North America have the highest incidence rates in the Northern Hemisphere, and Australia and New Zealand have the highest incidence in the south. The burden of melanoma in South America and Asia is relatively low.
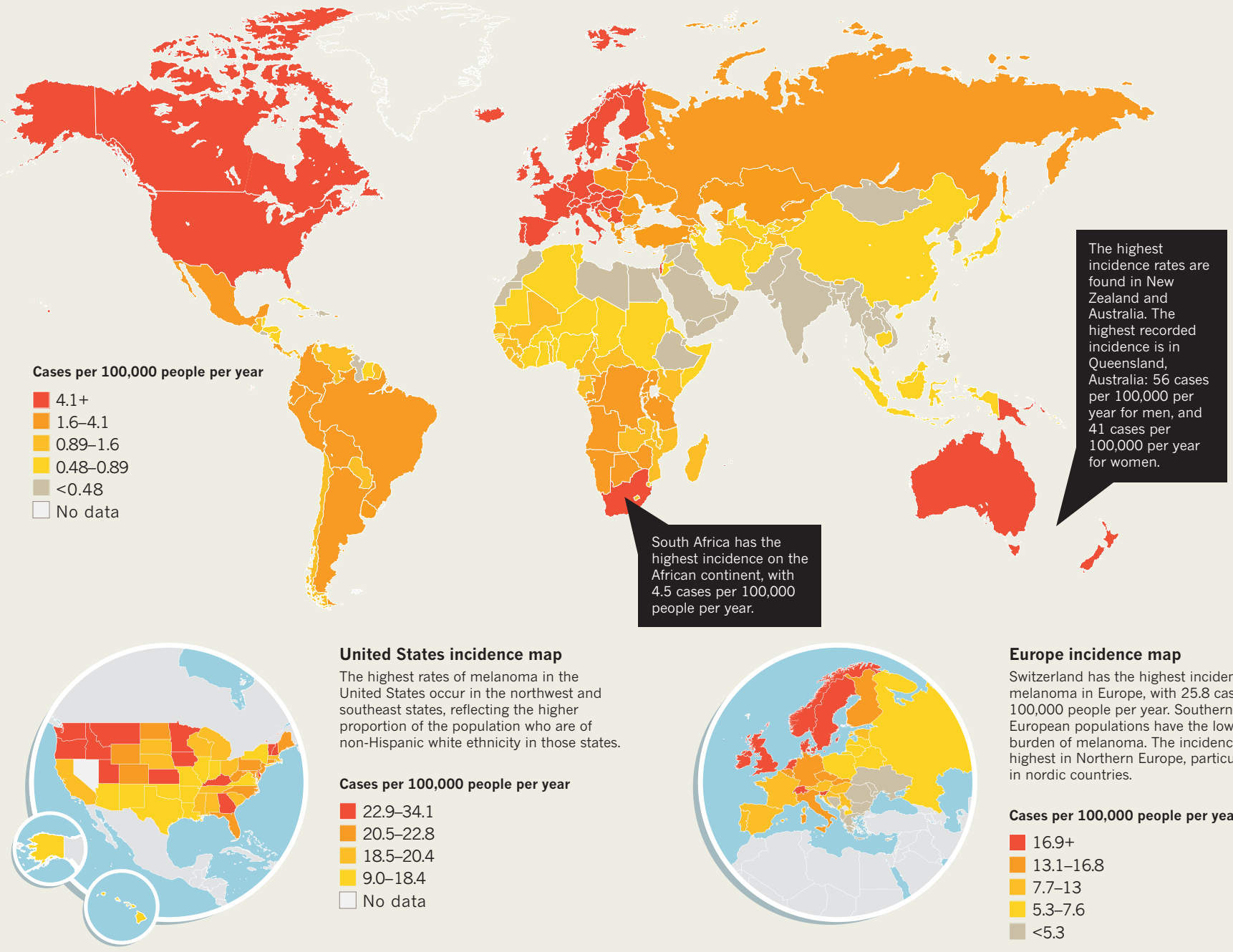

United States incidence map

The highest rates of melanoma in the United States occur in the northwest and southeast states, reflecting the higher proportion of the population who are of non-Hispanic white ethnicity in those states.

Cases per 100,000 people per yea

22.9-34.1

20.5-22.8

$18.5-20.4$

9.0-18.4

No data
African contince on the

4.5 cases per 100,000

people per year.

\section{BEYOND THE PALE}

Anyone can get melanoma but it usually afflicts people with light skin, and it is more common in men than in women. In the United States, it is more common among non-Hispanic whites than people of other races and ethnicities.

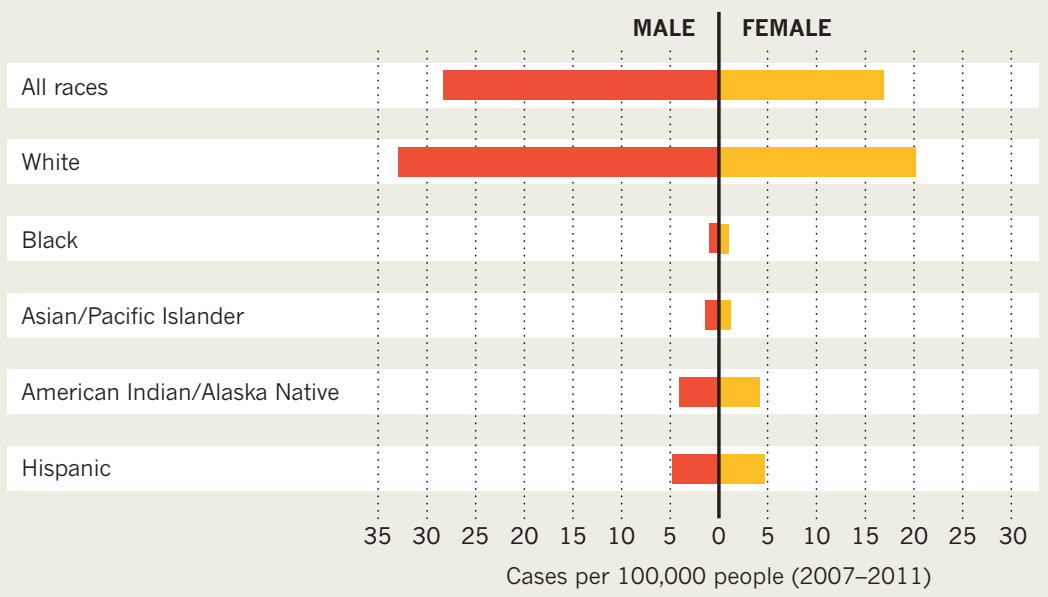

\section{TIME IN THE SUN}

In the United States, melanoma of the skin occurs most often in people aged between 55 and 64 .

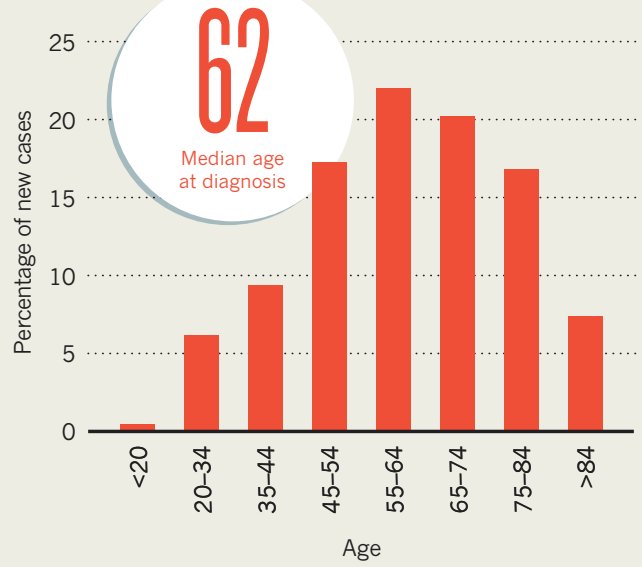

